\title{
A recombinant, infectious human parainfluenza virus type 3 expressing the enhanced green fluorescent protein for use in high-throughput antiviral assays
}

\author{
Jason P. Roth ${ }^{\mathrm{a}}$, Joseph K.-K. Lib, Donald F. Smee ${ }^{\mathrm{a}}$, John D. Morrey ${ }^{\mathrm{a}}$, and Dale L. Barnard ${ }^{\mathrm{a},{ }^{*}}$ \\ a Institute for Antiviral Research, Department of Animal, Dairy and Veterinary Sciences, Utah State \\ University, Logan, UT 84322-5600, USA \\ b Department of Biology, Utah State University, Logan, UT 84322-5305, USA
}

\begin{abstract}
The ability to rescue an infectious, recombinant, negative-stranded, RNA virus from a cDNA clone, has led to new opportunities for measuring viral replication from a viral expressed reporter gene. In this study, the enhanced green fluorescent protein (EGFP) gene was inserted into the human parainfluenza virus type 3 (HPIV-3) antigenome and a recombinant, infectious virus was rescued. Maximum EGFP expression levels, measured by fluorescence, were seen at day 3. Comparison of a three-day, viral expressed EGFP fluorescence assay to a seven-day, neutral red assay, based on complete cell destruction in virus infected MA-104 cells, yielded Z'-factor values of 0.83 and 0.70 , respectively. A three-day, endpoint EGFP-based antiviral assay and a seven-day, endpoint neutral red based antiviral assay were run in parallel to establish antiviral sensitivity profiles of 23 compounds based on selective index (SI) values. Using an SI threshold of 10, the EGFP-based antiviral assay had a sensitivity of $100 \%$ and a specificity of $54 \%$. Thus, the use of an EGFP-based antiviral assay for testing potential antiviral compounds against HPIV-3 in a high-throughput format may be justified.
\end{abstract}

\section{Keywords}

Human parainfluenza virus type 3; Enhanced green fluorescent protein; Recombinant virus; Antiviral assay

\section{Introduction}

The discovery of new antiviral drugs usually requires successful testing in vitro prior to further development. To measure the efficacy of these drugs, cell-based antiviral assays involving colorimetric and luminescence detection systems have been used. Colorimetric assays often measure absorption of neutral red or 3-(4,5-dimethylthiazol-2-yl)-2,5-diphenyltetrazolium bromide (MTT), which are taken up by intact cell cells as indicators of cell health. Neutral red measures membrane integrity by being absorbed by lysosomes, while MTT, once inside the cell, is reduced from a yellow tetrazolium salt into water-insoluble purple formazan crystals

\footnotetext{
*Corresponding author. Tel.: +1 435797 2696; fax: +1 435797 3959., E-mail address: E-mail: dale.barnard@ usu.edu (D.L. Barnard). Publisher's Disclaimer: This is a PDF file of an unedited manuscript that has been accepted for publication. As a service to our customers we are providing this early version of the manuscript. The manuscript will undergo copyediting, typesetting, and review of the resulting proof before it is published in its final citable form. Please note that during the production process errors may be discovered which could affect the content, and all legal disclaimers that apply to the journal pertain.
} 
by a mitochondrial reductase (Barnard et al., 2004; Finter, 1969; Watanabe et al., 1994). The time consuming and labor intensive nature of these methods have proven to be drawbacks (Smee et al., 2002). An alternative type of detection method is the CellTiter-Glo ${ }^{\circledR}$ Luminescent Cell Viability Assay (Promega, Madison, WI), which measures the ATP generated by intact cells (Noah et al., 2007). This assay claims to be more sensitive, less time consuming, and less labor intensive. Even though the luminescence assay may solve the disadvantages of the colorimetric assays, several issues arise that are also common to colorimetric assays as well.

A major problem with most cell viability assays is that they are designed to detect any cell death and do not differentiate between drug toxicity and viral cytopathic effect (CPE). By conducting a parallel drug toxicity assay, the two factors can be mathematically separated, although it is assumed that the differences measured in the assay are due to drug toxicity and $\mathrm{CPE}$ independently. This assumption ignores the possibility of positive or negative compounding effects from potential interactions between the drug and virus. A second problem is the inability for some viruses to produce detectable amounts of CPE and/or the long incubation times needed to reach complete cell monolayer destruction, which is often required to get accuracy in dye uptake assays. For the colorimetric and luminescent antiviral assay to be effective and reliable; complete cell destruction is necessary to obtain significant signal-tobackground ratios. Viral incubation times may extend up to 14 days for some viruses, which is problematic because the cell control may not survive that long. A third problem is the detection of syncytia that initially do not cause cell destruction. Early syncytia formation is problematic because, even though viral CPE can be visualized within a few days, syncytia absorb similar amounts of neutral red or MTT compared to uninfected cells (Smee et al., 2002). Therefore, it is necessary for the complete destruction of the syncytia before dye uptake assays will differentiate between uninfected cells and cells impacted by syncytial formation. Therefore, a detection system that can directly measure a change in CPE independent of drug toxicity in a shorter amount of time would be preferable.

One strategy of enhancing sensitivity and decreasing the incubation times of an assay would be to construct a recombinant virus that expresses a reporter gene. For example, a gene for a fluorescent protein could be cloned directly into a viral genome that would be expressed in proportion to virus replication and allow direct CPE measurement independently from drug toxicity. This has been done for antiviral compound screening purposes by inserting the gene for the green fluorescent protein into the genomes of the ebolavirus and cytomegalovirus (Marschall et al., 2000; Towner et al., 2005). Thus, for syncytial forming viruses, such as human parainfluenza virus type 3 (HPIV-3), a similar approach would be very useful in reducing the time needed to complete an antiviral assay.

Two recombinant HPIV-3 viruses have been constructed that express a green fluorescent protein, but they have not been extensively studied and validated for use in cell-based antiviral assays. One such virus, strain JS, was used to follow an infection of the recombinant virus in lung epithelium (Zhang et al., 2005). The second virus, strain 47885, was used to screen a library of potential antiviral compounds, yet specific details on replication differences of the recombinant virus, expressing the fluorescent protein, compared to the wild-type strain were not discussed (Mao et al., 2008). In this paper, a recombinant HPIV-3 virus (rHPIV3-EGFP) expressing the enhanced green fluorescent protein (EGFP) was rescued and evaluated for its use in antiviral assays by comparing it side-by-side with both the HPIV-3 wild-type (HPIV-3 WT) and the recombinant HPIV-3 (rHPIV3) strains. Slight differences in virulence between the rHPIV3-EGFP virus and the HPIV-3 WT virus in cell culture may validate the possibility of substituting the rHPIV3-EGFP for the HPIV-3 WT virus in primary, high-throughput antiviral assays. 


\section{Materials and methods}

\subsection{Cells and viruses}

Human cervical carcinoma cells (HeLa) were obtained from American Type Culture Collection (ATCC, Manassas, VA) and maintained at $37^{\circ} \mathrm{C}$ and $5 \% \mathrm{CO}_{2}$ in minimal essential medium (MEM, Hyclone Laboratories, Logan, UT) supplemented with 10\% fetal bovine serum (FBS, Hyclone Laboratories), $0.1 \mathrm{mM}$ non-essential amino acids (NEAA, Invitrogen, Carlsbad, CA), and $1 \mathrm{mM}$ sodium pyruvate (Invitrogen). Embryonic African green monkey kidney cells (MA-104) were obtained from ATCC and maintained at $37^{\circ} \mathrm{C}$ and $5 \% \mathrm{CO}_{2}$ in MEM supplemented with $10 \%$ FBS. A recombinant vaccinia virus that expresses the bacteriophage T7 RNA polymerase, vTF7-3, generously provided by Dr. Bernard Moss, was propagated in HeLa cells (Fuerst et al., 1986). HPIV-3 WT, isolate 14702, (J. Bouvin, Hosp. St. Justine, Montreal, Canada) was propagated in MA-104 cells. During the antiviral assays, MA-104 cells were incubated in MEM supplemented with $2 \%$ FBS and $50 \mu \mathrm{g} / \mathrm{ml}$ gentamicin (Sigma Chemical Company, St. Louis, MO).

\subsection{Antiviral compounds}

2-[(2R,3R,4S,5R)-3,4-Dihydroxy-5-(hydroxymethyl)oxolan-2-yl]-3-sulfanylidene-1,2,4triazin-5-one (2-thio-6-azauridine) was obtained from Sigma and the remainder of the antiviral compounds, including 1-[(2R,3R,4S,5R)-3,4-dihydroxy-5-(hydroxymethyl)oxolan-2yl]-1,2,4-triazole-3-carboxamide (ribavirin), 1-[(2R,3R,4S,5R)-3,4-dihydroxy-5(hydroxymethyl)oxolan-2-yl]-1,2,4-triazole-3-carboximidamide (ribamidine), 2-[(2R,3R,4S, 5R)-3,4-dihydroxy-5-(hydroxymethyl)oxolan-2-yl]-1,3-selenazole-4-carboxamide (selenazofurin), 1-[(2R,3R,4S,5R)-3,4-dihydroxy-5-(hydroxymethyl)oxolan-2-yl]-5ethynylimidazole-4-carboxamide (EICAR), 6-amino-1-[(2R,3R,4S,5R)-3,4-dihydroxy-5(hydroxymethyl)oxolan-2-yl]-5H-imidazo[4,5-c]pyridin-4-one (3-deazaguanosine), and 1-(4methoxybenzyloxy) adenosine, were obtained from the repository of the NIAID Antiviral Substances Program, NIH. Also obtained from the repository were CS-978, CS-1164, CS-1196, CS-1227, PSI-0194, PSI-5067, PSI-5095, PSI-5098, PSI-5452, PSI-5449, PSI-5741, PSI-5746, PSI-5747, PSI-5852, and PSI-5990 nucleoside analog compounds that were submitted by and used with permission from Dr. Michael Otto of Pharmasset, Inc. The DAS181 fusion protein, also obtained from the repository, was submitted by and used with permission from Dr. Fang Fang of NexBio, Inc. (Malakhov et al., 2006).

\subsection{Plasmid construction}

Three overlapping complementary DNA (cDNA) strands, encompassing viral bases 1-5267, 5249-11366, and 11284-15453, were generated from RNA isolated from a HPIV-3 WT, strain 14702 , infection. Forward and reverse primers were derived from the consensus sequence between three known HPIV-3 strains, 47885, JS, GPv (Galinski, 1991; Ohsawa et al., 1998; Stokes et al., 1992). To generate the 1-5267 cDNA segment the 5'CCGACGTCTTAATTAATACGACTCACTATAGGACCAAACAAGAGAAGAAACTT $-3^{\prime}$ forward primer, which contains AatII and PacI restrictions sites (bolded) and a T7 promoter (underlined) and the 5'-GGTCACCACAAGAGTTAGA-3' reverse primer were used. To generate the 5249-11366 cDNA segment the 5'-TCTAACTCTTGTGGTGACC-3' forward primer, which contains a natural BstEII restriction site (bolded) and the 5'-

ATTCATCCCAAGGGCAATA-3' reverse primer were used. To generate the 11284-15453 cDNA segment the 5'-AGAATGGTTATTCACCTGTTC-3' forward primer and the 5'GAGAAG CACTCTGT restriction site (bolded) with the two mutations, A to $\mathrm{C}$ and $\mathrm{T}$ to $\mathrm{G}$ (underlined), were used. The cDNA segments were inserted into the SmaI site of pUC19 (New England Biolabs, NEB, Ipswich, MA). Clones were sequenced in both directions to assure accuracy. An SphI site in the 5249-11366 cDNA segment was destroyed by mutating A to G, viral base position 8635, 
using the QuikChange ${ }^{\circledR}$ XL Site-Directed Mutagenesis (Stratagene, La Jolla, CA) kit and the forward primer, 5'-pCTTAGGAGCAAAGCGTGCTCAGAAAATGGACACTG-3', and reverse primer, 5'-pCAGTGTCCATTTTCTGAGCACGCTTTGCTCCTAAG-3'.

To confirm the sequence of the $3^{\prime}$ end of the HPIV-3 WT genome, a poly(A) tail was added to the $3^{\prime}$ end of the isolated HPIV-3 WT RNA using the Poly(A) Tailing Kit (Ambion, Austin, TX). The tailed RNA was amplified by RT-PCR using a 60 nucleotide (nt) poly(T) oligonucleotide, as the forward primer, and 5'-TCGTTTTAGATCCTTCTCAATCA-3', as the reverse primer. To sequence the $5^{\prime}$ end of the HPIV-3 WT genome, the $\mathrm{SMART}^{\mathrm{TM}}$ RACE cDNA Amplification Kit (Clontech) was used. An HPIV-3 WT specific primer, 5'-

GGAAGGAGCCATCGGCAAATCAGAAG-3', was used to prime cDNA synthesis and also used in the PCR amplification step as the forward primer. The PCR products from both the $3^{\prime}$ and 5' reactions were sequenced to complete the HPIV-3 WT 14702 genome (GenBank accession no. $\underline{\mathbf{E U 4 2 4 0 6 2}}$ ).

Two oligonucleotides were generated to contain a 14 base pair overlap between each other, 5 'TTTTTGTGCGCCCAATACGCAAACCGCCTCTCCCCGCGCGTTGGCCGTTAATTAA GAGGGTGA CCCTGCACAGAGTGCC-3' and 5'TTTTTGTAAAAAACCCCTCAAGACCCGTTTAGAGGCCCCAAGGGGTTATGCTAGT TAGGTACC CGGGCACTCTGTGCAG-3'. The oligonucleotides were annealed together and extended using Sequenase ${ }^{\mathrm{TM}}$ Version 2.0 DNA polymerase (USB Corporation, Cleveland, Ohio). The fragment was inserted into the SmaI site of pUC19 and named pUC19-A. The completed segment contained the PacI, BstEII, DraIII, SmaI, and KpnI sites (bolded), a T7 termination sequence (underlined), and two vaccinia virus termination sequences flanking each end (italicized). A second set of oligonucleotides were annealed, extended, and inserted into pUC19 in the same manner, $5^{\prime}$ -

ACCACACAGAGTGCTTCTCTTGTTTGGTGGGTCGGCATGGCATCTCCACCTCCTCG CGGTCCGACCT-3' and 5'-

GGCCGGTACC TCCCTTAGCCATCCGAGTGGACGACGTCCTCCTTCGGATGCCCAGGTCGGACC GCGA-3'. The completed segment, pUC19-R, contained the KpnI and DraIII restriction sites (bolded), the antigenomic hepatitis delta virus ribozyme (underlined) (Perrotta and Been, 1991), and the viral bases 15435-15462 (italicized). pUC19-R, digested with DraIII and KpnI, produced a 108 base pair (bp) segment that was inserted into the same sites of pUC19-A and was renamed pUC19-B. After destroying the native SphI site in pUC19-B and renamed pUC19$\mathrm{C}$, an adapter, using the oligonucleotides 5'-GTGACCGCGCATGCCCACAGA-3' and 5'GTGGGCATGCGCG-3', was inserted into the DraIII and BstEII sites of pUC19-C to encode a SphI site (bolded) and renamed pUC19-D. Next, the 5249-11366 cDNA segment was digested with BstEII and SphI, inserted into the same sites of pUC19-D, and renamed pUC19F. Then, the 1-5267 cDNA segment was digested with PacI and BstEII, inserted into the same sites of pUC19-F, and renamed pUC19-G. Finally, the 11284-15453 cDNA segment was digested with DraIII and SphI, inserted into the same sites of pUC19-G, and renamed pUC19H.

The 1-5267 cDNA segment, digested with AatII and BstEII, was inserted into the same sites of pACYC177 (NEB) and named p177-1Gen. The open reading frame of EGFP was amplified by PCR using pEGFP (Clontech, Mountain View, CA) as the template and the forward, 5'TTGACTAGAAGGTCAAGAACCTGCAGGTCGACTCTAGAGGAT-3', and reverse, 5' TTGACCTTCTAGTCAATGTCTTTAATCCTAAGTTTTTCTTATTT

ATTAACCGGCGCTCAGTTGG AAT-3', primers. Both primers contain a DrdI restriction site (bolded) on their $5^{\prime}$ ends. The reverse primer also includes the HPIV-3 WT gene end, intercistronic, and gene start signals (underlined). The $868 \mathrm{bp}$ band was purified and inserted into the SmaI site of pUC19, which was renamed pUC19-EGFP. pUC19-EGFP, digested with 
DrdI, produced an $852 \mathrm{bp}$ band that was inserted into the same site of p177-1Gen and named p177-1Gen-E. A 1-6119 genomic cDNA segment, containing EGFP, was digested out of p177-1Gen-E with PacI and BstEI, inserted into the same sites of pUC19-F, and named pUC19-I. Finally, the 11284-15453 cDNA segment was digested with DraIII and SphI, inserted into the same sites of pUC19-I, and renamed pUC19-J.

Three PCR products encompassing the nucleocapsid protein (NP), phosphoprotein (P), and large protein (L) were inserted into the SmaI site of pUC19 and named pUC19-NP, pUC19$\mathrm{P}$, and pUC19-L. The following three sets of forward and reverse primers were used: NP, 5'GAAGGTCAAGAAAAGGGAACTCT-3' and 5'-TTGATTCGATTAGTTGCTTCCA-3'; P, 5'-TGATGGAAAGCGACGCTAAA-3' and 5'-GGATCATTGGCAATTGTTGA-3'; L, 5'GCGTGCTCAGAAAATGGACA-3' and $5^{\prime}-$

CCTTAGGCTTAAAGATAAAGGTTAGGA-3'. The start codon (bolded) for the HPIV-3 WT accessory $\mathrm{C}$ protein, located on the $\mathrm{P}$ forward primer, was mutated from $\mathrm{T}$ to $\mathrm{C}$ (underlined) to silence its expression. pUC19-NP, pUC19-P, and pUC19-L were digested with Sall and $\mathrm{KpnI}$ and the $1.5 \mathrm{~kb}, 2 \mathrm{~kb}, 7 \mathrm{~kb}$ bands, respectively, were inserted into the same sites of pTNT $^{\mathrm{TM}}$ (Promega) and named pTNT-NP, pTNT-P, and pTNT-L.

\subsection{Rescue of infectious virus from cDNA}

HeLa cells, seeded in a 12-well plate, were infected with $5.4 \times 10^{5}$ PFU of vTF7-3 at 1 multiplicity of infection (MOI) for 1 hour. The virus and medium were removed and replaced with Opti-MEM ${ }^{\circledR}$ (Invitrogen), containing 0.1 mM NEAA. The three support plasmids, 0.8 $\mu$ gof pTNT-NP, $1.6 \mu \mathrm{g}$ of pTNT-P, and $0.04 \mu \mathrm{g}$ of pTNT-L, were cotransfected along with 0.4 $\mu$ gof either pUC19-H or pUC19-J, using Lipofectamine ${ }^{\mathrm{TM}} 2000$ (Invitrogen) for 4-5 hours at $37^{\circ} \mathrm{C}$. MEM supplemented with $20 \% \mathrm{FBS}, 0.1 \mathrm{mM}$ NEAA, $1 \mathrm{mM}$ sodium pyruvate, and 250 $\mu \mathrm{g} / \mathrm{mL}$ of Cytosine $\beta$-D-arabinofuranoside (Ara-C, Sigma) was added to each transfection and incubated for 48 hours at $37^{\circ} \mathrm{C}$. The transfected cells were scraped and the supernatants were frozen at $-80^{\circ} \mathrm{C}$. The rescued rHPIV3, pUC19-H transfection, and rHPIV3-EGFP, pUC19-J transfection, viruses were amplified on MA-104 cells, supplemented with $250 \mu \mathrm{g} / \mathrm{mL}$ Ara-C, for $3-4$ days at $37^{\circ} \mathrm{C}$. The cells were scraped and the supernatants were frozen at $-80^{\circ} \mathrm{C}$. Each virus was purified by picking agarose plugs over isolated plaques on MA-104 cells in the absence of Ara-C. Each plug was placed in MEM and froze at $-80^{\circ} \mathrm{C}$. The media, containing the plug and isolated virus, was used to infect MA-104 cells to amplify the virus for 3-4 days at $37^{\circ} \mathrm{C}$. The purification and amplification steps were repeated two more times. The rHPIV3, rHPIV3-EGFP, and HPIV3 WT viruses were amplified on MA-104 cells for 3 days at $37^{\circ} \mathrm{C}$. The infected cells were scraped and the supernatants were frozen at $-80^{\circ} \mathrm{C}$, which were used for further testing. Sequencing of the $5^{\prime}$ ends of the genomic RNA, isolated from rHPIV3 and rHPIV3-EGFP infections, was repeated using the SMART ${ }^{\mathrm{TM}}$ RACE cDNA Amplification Kit to confirm the DraIII genetic markers.

\subsection{Viral infectious assays}

2.5.1. Plaque assay-Duplicate dilutions of HPIV-3 WT, rHPIV3, and rHPIV3-EGFP, were used to infect MA-104 cells in quadruplicate. Virus was absorbed for 2 hours, after which, the virus was removed and replaced with an overlay of $1 \%$ SeaPlaque ${ }^{\circledR}$ low-melting agarose (ISC BioExpress ${ }^{\circledR}$, Kaysville, UT) supplemented with MEM and $0.2 \%$ sodium bicarbonate and incubated for $2-3$ days at $37^{\circ} \mathrm{C}$. Cells were fixed with $3.6 \%$ formaldehyde for 2 hours at room temperature, after which, the formaldehyde and agarose overlay was removed and $0.5 \%$ crystal violet was added for 5 minutes. After removal of the dye and one rinse with phosphate buffered saline (PBS), the stained plaques were counted. Viral titers were compared and statistically analyzed by unpaired, two-tailed student's t-test using the Microsoft ${ }^{\circledR}$ Office Excel 2003 software (Redmond, WA). In addition, plaques produced by rHPIV3-EGFP were also photographed using an Eclipse TS100 microscope (Nikon, Melville, NY), CoolSNAP digital 
camera, and RS Image $^{\mathrm{TM}}$ software, version 1.7.3, (both from Roper Scientific, Photometrics, Tucson, AZ). Fluorescent photographs were taken with the same equipment except under UV light and the B-2A fluorescent filter combination was used, which incorporates excitation wavelengths between $450-490 \mathrm{~nm}$ and emission filter wavelengths greater than $515 \mathrm{~nm}$.

2.5.2. One-step growth curve-Duplicate 12 -well plates were seeded with MA-104 cells and infected with $1.4 \times 10^{6} \mathrm{PFU}$ of HPIV-3 WT, rHPIV3, and rHPIV3-EGFP viruses, separately, at an $\mathrm{MOI}=2$. After virus was absorbed for 2 hours at $37^{\circ} \mathrm{C}$, virus was removed, replaced with fresh MEM supplemented with $2 \% \mathrm{FBS}$, and incubated at $37^{\circ} \mathrm{C}$. Individual cells were scraped and the supernatants harvested every six hours starting at the time of virus exposure and frozen at $-80^{\circ} \mathrm{C}$. At time 0 , virus was added but then immediately removed and replaced with fresh medium. Each time point for each virus was plaque titered in quadruplicate following the same method as described above. Each growth curve was compared to the other two curves, individually, and statistically analyzed by analysis of variance (ANOVA) using the Microsoft ${ }^{\circledR}$ Office Excel 2003 software.

2.5.3. Cytopathic effect assay-Ninety-six-well plates were seeded with MA-104 cells and infected with $3.9 \times 10^{3} \mathrm{PFU}$ of either the HPIV-3 WT or rHPIV3-EGFP virus in duplicate at an MOI $=0.1$ in quadruplicate wells. The plates were incubated at $37^{\circ} \mathrm{C}$ and on each day, including the day of infection, the cells were stained with $0.034 \%$ neutral red (NR) for 2 hours at $37^{\circ} \mathrm{C}$, washed once with PBS, and the NR extracted with ethanol:Sörenson's citrate buffer for 30 min while rocking at room temperature. Absorbance, at 540 and $405 \mathrm{~nm}$ wavelengths, was read with an Opsys $\mathrm{MR}^{\mathrm{TM}}$ spectrophotometer and Revelation Quicklink software, version 4.24 (both from Dynex Technologies, Chantilly, VA). The two curves was compared and statistically analyzed by ANOVA.

2.5.4. QRT-PCR assay-Ninety-six-well plates were seeded with MA-104 cells and infected with $7.8 \times 10^{4} \mathrm{PFU}$ of HPIV-3 WT and rHPIV3-EGFP viruses, separately, in duplicate at an $\mathrm{MOI}=2$. At specific time points; 0, 12, 24, and 36 hours, uninfected and infected cells were harvested using Cells Direct Resuspension and Lysis Buffers (Invitrogen). Each lysate was used as the template for two different reverse transcriptase (RT) reactions. One reaction used a primer specific for the HPIV-3 genome, $5^{\prime}$ -

AATTATAAAAAACTTAGGAGTAAAG-3', and the other reaction used an Oligo(dT)20 primer (Invitrogen). The primers used to PCR amplify the cDNA products from the RT reactions include 5'-CGTTATAGTGCTGCCACAAAGAATAA[FAM]G-3' and 5'-

ATGGAAGACCAGACGTGCATC-3', for genomic replication, and 5'CGATTAAGGAAAGCGACCTGTAAGTAAT[FAM]G-3' and 5'-

GAGACACAAATTAGGCGGGAGAT-3', for L gene transcription. Platinum ${ }^{\circledR}$ Quantitative PCR SuperMix-UDG (Invitrogen), $200 \mathrm{nM}$ of the forward and reverse $\mathrm{LUX}^{\mathrm{TM}}$ primers (Invitorgen), and $1 / 10^{\text {th }}$ of the RT reaction were mixed and added, in triplicate, to Hard-Shell 96-well skirted PCR plates (Bio-Rad Laboratories, Hercules, CA). The reaction was run on a DNA Engine Opticon 2 Real-Time PCR Detection System (MJ Research, Waltham, MA). The Opticon Monitor ${ }^{\mathrm{TM}}$ software, version 3.1.32 (Bio-Rad Laboratories) was used to calculate relative expression differences, Delta- $\mathrm{C}_{\mathrm{T}}$, at each time point for each virus, using the 0 hour for each virus as the calibrator (Pfaffl, 2001). For each assay, the two curves were compared and statistically analyzed by ANOVA.

\subsection{Antiviral sensitivity assay}

An antiviral CPE assay was used to evaluate the antiviral sensitivity profiles of the HPIV-3 WT and rHPIV3-EGFP viruses (Barnard et al., 2001; Cavanaugh et al., 1990). Briefly, three compounds: ribavirin (positive control), 2-thio-6-azauridine, and DAS181, were plated in four ten-fold dilutions in five replicates on 96-well plates seeded with MA-104 cells using starting 
concentrations of $1000 \mu \mathrm{g} / \mathrm{mL}, 100 \mu \mathrm{g} / \mathrm{mL}$, and $1 \mu \mathrm{g} / \mathrm{mL}$, respectively. Two of five replicates were toxicity controls with no virus added, while the other three replicates were infected with $3.9 \times 10^{3} \mathrm{PFU}$ of either the HPIV-3 WT or the rHPIV3-EGFP virus at an MOI $=0.1$. The plates were incubated at $37^{\circ} \mathrm{C}$ for 7 days and, after which, the cells of each plate were stained with NR following the same method as described above. The assays were done three times. Fifty percent effective concentrations $\left(\mathrm{EC}_{50}\right)$ were calculated by linear regression using percents of untreated, uninfected cell and untreated, infected virus controls. $\mathrm{EC}_{50}$ values were compared and statistically analyzed by the unpaired, two-tailed student's t-test.

\subsection{EGFP expression assays}

Ninety-six-well plates were seeded with MA-104 cells and infected with $3.9 \times 10^{4} \mathrm{PFU}$ of rHPIV3-EGFP in duplicate at an MOI $=1$. Quadruplicate four ten-fold dilutions of virus were plated and the cultures incubated at $37^{\circ} \mathrm{C}$. Each day for 8 days, including the day of infection, the medium was removed and the cell cells were washed with PBS and fresh PBS was added. On the day of infection, the virus was added but then immediately removed and the cells were washed with PBS. EGFP fluorescence was measured with the FMax ${ }^{\circledR}$ fluorometer, using the $485 \mathrm{~nm}$ excitation and $538 \mathrm{~nm}$ emission filters, and recorded with SOFTmax ${ }^{\circledR}$ PRO software, version 1.3.1, (both from Molecular Devices, Union City, CA).

Duplicate 96-well plates were seeded with MA-104 cells. On each plate, 16 wells were infected with $3.9 \times 10^{3} \mathrm{PFU}$ of rHPIV3-EGFP at an MOI $=0.1$, while 16 wells were left uninfected as a cell control and 16 wells were left unseeded as a no-cell background control. The plates were incubated for 3 days at $37^{\circ} \mathrm{C}$. After incubation, the uninfected and infected cells and unseeded wells were washed with PBS, replaced with fresh PBS, and fluorescence was measured using the FMax ${ }^{\circledR}$ fluorometer. The traditional NR-based assay and Vybrant ${ }^{\circledR}$ MTT Cell Proliferation Assay (Invitrogen) were done following the same 96-well plate format except that cells were treated and results were measured after complete infected cell lysis on day 7 . The cells for the NR assay were stained following the same procedure described earlier, while the manufacture's quick protocol was followed for staining of the cells for the Vybrant ${ }^{\circledR}$ MTT assay. The absorbance values for cells treated with MTT were measured using the $540 \mathrm{~nm}$ wavelength, Opsys $\mathrm{MR}^{\mathrm{TM}}$ spectrophotometer, and Revelation Quicklink software. The CellTiter-Glo ${ }^{\circledR}$ Luminescent Cell Viability Assay (Promega) was also performed using the same 96-well format except that MA-104 cells were seeded on white, half area 96-well plates with a clear bottom. Therefore, plating volumes were reduced by $50 \%$ and the CellTiter-Glo ${ }^{\circledR}$ reagent was reduced by $75 \%$, while otherwise following the manufacture's protocol. Luminescence was measured using the Centro LB 960 luminometer and recorded with MikroWin 2000 software, version 4.34 (both by Berthold Technologies, Oak Ridge, TN).

\subsection{EGFP-based antiviral assay}

Six 96-well plates were seeded with MA-104 cells to evaluate the NR and EGFP assays in parallel. A format was used allowing seven compounds to be tested per plate. Each compound was plated using four ten-fold dilutions in triplicate and starting the concentration at $1000 \mu \mathrm{g} /$ $\mathrm{mL}$ for ribavirin (positive control), and ribamidine; $100 \mu \mathrm{g} / \mathrm{mL}$ for 2-thio-6-azauridine, 3deazaguanosine, 1-(4-methoxybenzyloxy) adenosine, selenazofurin, and EICAR; $100 \mu \mathrm{M}$ for CS-978, CS-1164, CS-1196, CS-1227, PSI-0194, PSI-5067, PSI-5095, PSI-5098, PSI-5452, PSI-5449, PSI-5741, PSI-5746, PSI-5747, PSI-5852, and PSI-5990; and $1 \mu \mathrm{g} / \mathrm{mL}$ for DAS 181. Compounds that were reconstituted in DMSO were diluted down to working concentrations of $0.5 \%$ DMSO and less to eliminate cell toxicity due to the DMSO. Two of the replicates were infected with $3.9 \times 10^{3} \mathrm{PFU}$ of rHPIV3-EGFP, at an MOI $=0.1$, while the remaining replicate served as a toxicity control with no virus added. Three of the plates were incubated at $37^{\circ} \mathrm{C}$ for 3 days, after which, the toxicity and cell control cells were stained with NR following the same procedure described earlier. NR fluorescence was measured with the FMax ${ }^{\circledR}$ fluorometer, 
using the $544 \mathrm{~nm}$ excitation and $612 \mathrm{~nm}$ emission filters. The untreated virus control and treated, infected cells were washed with PBS, fresh PBS was added, and the fluorescence was measured with the FMax ${ }^{\circledR}$ fluorometer, using the $485 \mathrm{~nm}$ excitation and $538 \mathrm{~nm}$ emission filters. The other three plates were assayed using the traditional colorimetric NR assay. After incubation for 7 days at $37^{\circ} \mathrm{C}$, the cells were stained with NR following the same procedure described earlier. For the NR assay, $\mathrm{EC}_{50}$ and $50 \%$ cell inhibitory concentrations $\left(\mathrm{IC}_{50}\right)$ were calculated by linear regression from percents of untreated, uninfected cell and untreated, infected virus controls. For the $\mathrm{EGFP}$ assay, $\mathrm{EC}_{50}$ values were calculated by linear regression using percents of untreated, infected virus controls and $\mathrm{IC}_{50}$ values were also calculated by linear regression using percents of untreated, uninfected cell control. The $\mathrm{EC}_{50}$ and $\mathrm{IC}_{50}$ values for each compound for both assays were compared and statistically analyzed by unpaired, twotailed student's t-test. A selectivity index (SI) was calculated for each compound for each assay using the formula: $\mathrm{SI}=\mathrm{Mean} \mathrm{IC}_{50} / \mathrm{Mean} \mathrm{EC}_{50}$. Compounds were sorted into positive, $\mathrm{SI} \geq 10$, and negative, SI $<10$, categories for the combination of NR and EGFP assays. Using the NR assay as the gold standard, sensitivity, true positives/(true positives+false negatives), and specificity, true negatives/(true negatives+false positives), were calculated.

\section{Results}

\subsection{The successful insertion of the EGFP gene into the HPIV-3 antigenome and rescue of an infectious, recombinant HPIV-3 expressing the fluorescent protein}

A DrdI restriction site was found between the $\mathrm{N}$ gene's start signal and start codon of the HPIV-3 WT genome that was used to facilitate the insertion of the EGFP gene. Therefore, both the forward and reverse primers that were used to amplify the EGFP open reading frame were designed to contain a DrdI restriction site on their 5' ends. The HPIV-3 WT gene end, intercistronic, and gene start signals were also encoded onto the reverse primer so that the inserted EGFP gene would be recognized as an additional HPIV-3 WT gene (Fig. 1A). The "Rule of Six" was followed to generate an 852 bp EGFP gene segment. The rule suggests that viral replication is most efficient when the viral genome length is a factor of six, which is most likely due to a single nucleocapsid protein binding to six genomic ribonucleotides (Calain and Roux, 1993;Durbin et al., 1997). In constructing the recombinant HPIV-3 expressing EGFP, the presence of three $\mathrm{G}$ ribonucleotides, which are equally separated by 5 ribonucleotides starting 79 ribonucleotides from the $5^{\prime}$ end of the antigenome, had to be manipulated. This location represents one complete turn of the 3-dimensional helical structure of the nucleocapsid encased RNA genome and is thought to co-regulate viral replication perhaps through the assembly and binding of the viral polymerase-phosphoprotein complex with the nucleocapsids (Tapparel et al., 1998). The EGFP forward primer interrupted this natural pattern but the problem was solved by adding the three $\mathrm{G}$ residues in the forward primer at positions 11,17 , and 23. Before the addition of the EGFP gene segment into the antigenome, the 1-5267 cDNA segment was cloned into the pACYC177 plasmid to circumvent multiple DrdI restriction sites located in the pUC19 plasmid. The resulting 1-6119 cDNA segment, now encoding the gene for EGFP, was then cloned into the pUC19 plasmid, already containing the 5249-11366 cDNA segment. Finally, the addition of the 11284-15453 cDNA segment to the construct resulted in a complete, infectious, recombinant HPIV-3 virus, expressing the EGFP gene.

To demonstrate the successful rescue and isolation of two rHPIV3 strains, one with and one without the EGFP gene insertion, sequences surrounding three genetic markers were aligned and compared to the HPIV-3 WT virus, isolate 14702 (Fig. 1B). RNA isolated from rHPIV3EGFP, rHPIV3, and HPIV-3 WT infections was amplified by RT-PCR. The sequences generated from the 5' RACE RT-PCR, containing the DraIII restriction site, confirmed the Ato-C and T-to-G mutations. These two mutations created a unique DraIII restriction site present only in the recombinant viruses and allowed for the insertion of the final 11284-15453 cDNA 
segment and completion of the recombinant viruses. The third genetic marker was also confirmed by aligning sequences generated from the $5^{\prime}$ end of the $\mathrm{L}$ gene from all three viruses. The A-to-G mutation eliminated one of two natural SphI restriction sites located in L gene portion of the HPIV-3 WT virus. The second SphI restriction site was used to insert both the 5249-11366 and 11284-15453 cDNA segments. These PCR products were also digested with SphI and separated on an agarose gel to show that HPIV-3 WT was digested in the presence of SphI, while the two recombinant viruses were not (Fig. 1C).

Plaques formed by rHPIV3-EGFP were stained with crystal violet and analyzed by bright field microscopy. The viral induced syncytia absorbed more crystal violet compared to surrounding uninfected cells (Fig. 2A). The syncytia from the same plaque were visualized by fluorescent microscopy and had high concentrations of green fluorescence (Fig. 2B). On the other hand, plaques formed by HPIV-3 WT did not produce fluorescence, data not shown. This result demonstrates a direct correlation between viral growth, syncytia formation, and EGFP expression.

\section{2. rHPIV3-EGFP replication is slightly attenuated due to the additional gene}

The infectious virus present in the stocks of all three viruses was plaque titered and the means, \pm standard deviation, of duplicate assays were found to be: $2.9 \pm 0.41 \times 10^{7} \mathrm{PFU} / \mathrm{ml}$ for HPIV-3 WT, $2.8 \pm 0.22 \times 10^{7} \mathrm{PFU} / \mathrm{ml}$ for rHPIV3, and $1.9 \pm 0.49 \times 10^{7} \mathrm{PFU} / \mathrm{ml}$ for rHPIV3-EGFP. The infectious virus titer for rHPIV3 was not significantly different compared to HPIV-3 WT ( $p>0.01$ ) whereas, rHPIV3-EGFP was significantly lower compared to both HPIV-3 WT and rHPIV3 ( $\mathrm{p}<0.01$ ). The addition of the EGFP gene into the HPIV-3 genome appeared to attenuate rHPIV3-EGFP compared to either the WT or recombinant strains. However, the process of creating and rescuing the recombinant virus and/or the presence of the three genetic markers did not cause attenuation of rHPIV 3 because no significant reduction in virus titer was seen. For all subsequent experiments the volume of virus inoculums were adjusted so that equal PFUs were added. In addition, the replication kinetics of the three viruses, HPIV-3 WT, rHIPV3 and rHPIV-EGFP were measured to confirm the attenuation of rHPIV3-EGFP compared to the wild-type and recombinant viruses. The growth curves for rHPIV3 and HPIV-3 WT were very similar, with no significant differences ( $\mathrm{p}>0.01$ ) (Fig. 3A). However, the growth curve for rHPIV3-EGFP was significantly delayed compared to the growth curves for both HPIV-3 WT and rHPIV3 $(p<0.01)$. During the initial stages of infection, the attenuated growth of rHPIV3-EGFP compared to both the wild-type and recombinant viruses can be seen, yet it appears that the replication of the rHPIV3-EGFP virus may recover and amplify itself to similar levels compared to the other two viruses during the later stages of replication. This result confirmed that the addition of an additional gene into the HPIV-3 genome may be the cause of attenuation.

The CPE produced by rHPIV3-EGFP and HPIV-3 WT viruses in infected MA-104 cells was monitored for 7 days and measured by NR uptake until complete infected cell lysis occurred, verified by microscopic examination. Complete cell lysis induced by both viruses occurred at the same time on day 7 and no significant difference in either curve was detected (p>0.01) (Fig. $3 \mathrm{~B})$. This result contradicted previous results showing attenuation in the replication of the rHPIV3-EGFP virus, but the result supports the idea that rHPIV3-EGFP is able to recover and replicate up to HPIV-3 WT standards.

To determine how the additional gene may have contributed to the attenuation seen during the onset of infection, a QRT-PCR assay was done to measure genomic replication and L gene transcription. An HPIV-3 specific primer that annealed to the intergenic sequence between the fusion and hemagglutinin-neuraminidase genes of the viral, negative-sense RNA, only allowing binding to viral, genomic RNA rather than viral mRNA or viral, positive-sense, antigenomic RNA, was used as a primer for the RT reaction. An oligo(dT) 20 primer was used to 
prime the RT reaction for the $\mathrm{L}$ gene transcription measurement, binding only viral mRNA and not viral genomic RNA. Relative expression differences were calculated and normalized, using the 0 hour for each virus as the calibrator, according to the calculations developed by Pfaffl (2001). A calibrator was used to normalize the amount of mRNA transcripts or genomic copies generated during the infections with the amount that was added at the time of infection for each virus. L gene transcription (Fig. 3C) and genomic replication (Fig. 3D) were significantly reduced in an rHPIV3-EGFP infection compared to the HPIV-3 WT infection $(p<0.01)$. The additional gene present in the HPIV-3 genome caused a reduction in the amount of viral mRNA transcripts and genomic copies that were normally generated in a WT infection.

\section{3. rHPIV3-EGFP is slightly more sensitive to antiviral compounds}

To further study the consequences of the attenuation detected for rHPIV3-EGFP replication, three known antiviral compounds that inhibit HPIV-3 were tested. The three compounds include two nucleoside analogs, ribavirin and 2-thio-6-azauridine, and a recombinant fusion protein between a sialidase catalytic domain and cell surface-anchoring sequence, DAS181 (Malakhov et al., 2006). $\mathrm{EC}_{50}$ values, which are the concentration of compounds that inhibit $50 \%$ of virus replication, were calculated for each compound for both HPIV-3 WT and rHPIV3EGFP viruses. The mean, \pm standard deviation, of three replicates were found to be: $35 \pm 2.5$ $\mu \mathrm{g} / \mathrm{mL}$ and $19 \pm 4.9 \mu \mathrm{g} / \mathrm{mL}$ for ribavirin, respectively; $1100 \pm 58 \mathrm{ng} / \mathrm{mL}$ and $630 \pm 75 \mathrm{ng} / \mathrm{mL}$ for 2-thio-6-azauridine, respectively; and $53 \pm 2.3 \mathrm{ng} / \mathrm{mL}$ and $13 \pm 2.3 \mathrm{ng} / \mathrm{mL}$ for DAS181, respectively. The rHPIV3-EGFP virus was significantly more sensitive to inhibition by these compounds than was the wild-type virus $(\mathrm{p}<0.05)$. This supports the idea that the rHPIV3EGFP virus was attenuated.

\subsection{Using EGFP expression as a measure of viral infectivity leads to a faster and more robust assay}

To determine the earliest possible day that a potential EGFP-based assay could be completed, EGFP expression by rHPIV3-EGFP was measured. The fluorescence emitted from the viral expressed EGFP was measured each day in rHPIV3-EGFP infected MA-104 cells at various MOIs of virus. EGFP expression rose in a dose-dependant manner beginning at day 1, peaked on day 3 regardless of MOI, and leveled off thereafter (Fig. 4). Even though, the infection at MOI $=1$ resulted in the greatest fluorescence, a large amount of fluorescence was still detected for the other three MOIs as well. The infection at MOI $=0.1$ was equivalent to the concentration of virus used in typical antiviral assays, so this concentration of virus was used in further testing.

To compare the three-day, EGFP-based assay to the traditional NR-based assay, Vybrant ${ }^{\circledR}$ MTT Cell Proliferation, and CellTiter-Glo ${ }^{\circledR}$ Luminescent Cell Viability assays, the Z'-factors, signal-to-background ratios, and signal-to-noise ratios were calculated (Table 1). The Z'-factor is a statistical calculation that assesses the quality of a high-throughput screening assay and predicts the potential of the assay if the number of samples were scaled up. $Z^{\prime}$-factors were computed for each assay and compared using two different fitness tables (Kraybill, 2005;Zhang et al., 1999). Ultimately, a higher $Z$ '-factor value means the assay is more robust when it is used in a high-throughput format. The three-day, EGFP-based assay, 0.83 , proved to be more robust than the other three seven-day assays: 0.70 for the NR-based assay, 0.73 for the CellTiter-Glo ${ }^{\circledR}$ Luminescent Cell Viability assay, and 0.50 for the Vybrant ${ }^{\circledR}$ MTT Cell Proliferation assay. According to the fitness tables, the EGFP-based, NR-based, and CellTiter$\mathrm{Glo}^{\circledR}$ Luminescent Cell Viability assays were all considered to be good to excellent assays. On the other hand, the Vybrant ${ }^{\circledR}$ MTT Cell Proliferation assay was considered to be borderline excellent/marginal on one table and at the recommended minimum level for the second table. For the signal-to-background ratios, the EGFP assay, with a value of 241, again proved to be superior showing excellent signal to background signal separation. The NR assay, value of 65 , resulted in good separation, whereas both the CellTiter-Glo ${ }^{\circledR}$ Luminescent, value of 6, and 
Vybrant ${ }^{\circledR}$ MTT assays, value of 7, resulted in poor separation of signal to background signal. In addition, the EGFP assay, with a signal-to-noise ratio of 4057, again proved to be superior to the other three assays, signal-to-noise ratios of: 301 for NR, 59 for CellTiter-Glo ${ }^{\circledR}$, and 60 for Vybrant ${ }^{\circledR}$ MTT, by showing excellent signal to background variability separation.

\subsection{Comparison of a seven-day, NR-based antiviral assay and a three-day, EGFP-based antiviral assay}

To investigate the practicality of using rHPIV3-EGFP in an antiviral screening assay, a panel of 23 antiviral compounds were selected that had shown antiviral activity against HPIV-3 in past screens (data not shown). A standard seven-day, NR-based assay and a three-day, EGFPbased assay, using the same virus stock, were done in parallel using 23 compounds, which included 22 nucleoside analogs and the one fusion protein, DAS181 (Table 2). A selective index (SI) value $\leq 3$ was considered not active, SI values between 4 and 9 slightly active, between 10 and 49 moderately active, and $\geq 50$ highly active. Compounds with SI values $\geq 10$ dictated if an antiviral drug would be further evaluated in additional assays. Using the threshold SI value of 10 , the three-day, EGFP-based assay had a sensitivity of $100 \%$ and specificity of $54 \%$, compared to the seven-day NR assay. Using the seven-day NR assay as the gold standard, six compounds were falsely identified as selective inhibitors of virus replication using the rHPIV3-EGFP virus in the antiviral assay, which led to the 54\% specificity. These six compounds showed an increase in the SI value over the threshold of 10 in the EGFP assay but under the threshold in the NR assay. Of these six, PSI-5449 was not active in the NR assay but was moderately active in the EGFP assay. An additional four, ribamidine, selenazofurin, PSI-5852, and PSI-5095, were considered slightly active in the NR assay and moderately active in the EGFP assay. The remaining compound, CS-1196 was considered slightly active in the NR assay and highly active in the EGFP assay. A factor that contributed to the differences in selectivity detected in each assay was the lack of toxicity found in cells exposed to compound in the EGFP assay. The toxicity of a drug is determined by the concentration at which it is lethally toxic to $50 \%$ of the cells present in the assay, termed $\mathrm{IC}_{50}$. No toxicity was observed for all 6 compounds falsely identified as selective inhibitors in the EGFP assay and the $\mathrm{IC}_{50}$ values for four out of the six compounds were significantly decreased in the seven-day NR assay $(\mathrm{p}<0.05)$. The difference in toxicity was probably due to the accumulation of toxicity during the seven-day incubation period of the NR assay. On the other hand, when the rHPIV3EGFP virus was measured by the EGFP fluorescent assay the resulting $\mathrm{EC}_{50}$ values were significantly lower $(\mathrm{p}<0.05)$ for three out of the six drugs compared to the NR assay. This result will also contribute to the higher selectivity detected for these compounds in the EGFP assay compared to the selectivity of these compounds evaluated in the NR assay. The combination of an increased $\mathrm{IC}_{50}$ and a decreased $\mathrm{EC}_{50}$ undoubtedly increased the SI for these six compounds and falsely suggested further evaluation, explaining the low specificity of the EGFP assay. Overall, for most other compounds a trend is seen when an increase in the SI value was detected in the EGFP fluorescent assay compared to the NR assay. In most cases, the increased SI can be contributed to either a significant decrease in the $\mathrm{EC}_{50}$, significant increase in the $\mathrm{IC}_{50}$, or a combination of both scenarios.

\section{Discussion}

The purpose of this study was to investigate the possibility of substituting rHPIV3-EGFP for HPIV-3 WT in the initial screening of potential antiviral compounds. First, attenuation of either the rHPIV3 or rHPIV3-EGFP, compared to HPIV-3 WT, was studied to determine if loss of virulence had occurred due to either the assembly and rescue of a recombinant clone or the addition of the EGFP gene. The rescued rHPIV3 virus has three genetic mutations that made it distinguishable from HPIV-3 WT. Although these three genetic markers were detected in the rescued virus, they did not attenuate the recombinant virus. Two of these markers reside 
in the $3^{\prime}$ untranslated region of the HPIV-3 antigenome and could have disrupted regulatory promoters to attenuated rHPIV3; they did not. On the other hand, the addition of the EGFP gene into the rHPIV3 virus, which increased the length of the viral genome by only $5 \%$ and added a seventh, distinctive gene unit, did significantly attenuate the rescued rHPIV3-EGFP virus. Even though, the attenuation was statistically significant, only a 1.5 -fold reduction in rHPIV3-EGFP titers was seen. This may be of no significance because a wild-type virus grown in varying cell culture conditions: higher or lower passaged cells, confluent or less than confluent cells, variation in the media formulations, or incubation in varying conditions, may inhibit or accelerate virus replication. A 10-fold, or greater, reduction in virus titer would indicate severe attenuation and would suggest that the new virus was indeed biologically different than the wild-type strain. In support of this point, the CPE produced by rHPIV3-EGFP was not significantly inhibited or accelerated compared to the CPE produced by HPIV-3 WT throughout the duration of a viral infection. Although, decreased viral titers and slower viral replication was detected for the rHPIV3-EGFP virus, CPE produced by each virus remained the same.

The attenuation of rHPIV3-EGFP can be attributed to the combination of the small increase in genome length and the addition of a foreign gene, which contributed to the significantly reduced viral genomic replication and mRNA transcription. The viral polymerase terminates and reinitiates transcription at each gene junction inconsistently, resulting in a reduction of downstream gene transcription and expression in a gradient fashion (Cattaneo et al., 1987;

Homann et al., 1990). Thus, the first of six viral genes, NP, should be expressed at significantly higher levels compared to the last $\mathrm{L}$ gene. Therefore, the insertion of the EGFP gene into the first viral gene position should result in a reduction in mRNA transcription in all downstream viral genes due to further inconsistent termination and reinitiation of the viral polymerase. This phenomenon was confirmed when transcription of the L gene was reduced in the rHPIV3EGFP virus infection compared to the HPIV-3 WT virus infection. In addition, genomic replication was also reduced, perhaps due to the overall decline in the expression of necessary viral replication proteins. A significant reduction in viral transcription could also lead to a reduction in translation of the viral transcripts. Overall, less viral proteins would be available for replication purposes resulting in less efficient viral replication. Thus, less virions would be assembled because of the reduction in viral proteins and genomic RNA strands resulting in an attenuated virus. Furthermore, ribavirin and 2-thio-6-azauridine inhibit inosine monophosphate dehydrogenase and orotidine monophosphate decarboxylase, respectively, and can be classified as nucleoside analogs, which may be incorporated into the viral RNA strands and interfere with further protein translation and genome replication (De Clercq, 1993; Sidwell, 1996). The reduced $\mathrm{EC}_{50}$ values are probably related to the reduction in mRNA transcription and genomic replication; therefore, less compound is needed to incorporate into the RNA strands and inhibit viral expression. On the other hand, DAS181 eliminates the host cell receptor needed for viral entry and inhibits virion binding and absorption (Malakhov et al., 2006). The reduced $\mathrm{EC}_{50}$ values are most likely due to the reduction in viable virions produced by the attenuated virus; therefore, less compound is required to prevent virion attachment. The consequence of a slightly attenuated virus is the possibility of a reduced $\mathrm{EC}_{50}$ value, which may increase the SI value above the threshold of 10 and result in a false positive, meaning that the same compound may not inhibit the wild type virus as much. This consequence is acceptable in the initial screening of a high-throughput assay because the false positive compounds would be retested in the presence of the wild-type virus and if they were true, false positives, they would be eliminated in the second round of screening.

The potential of using a recombinant virus that expresses a reporter gene to measure viral replication leads to the possibility of detecting the virus earlier in the assay. Assays that use dyes or enzymes, like NR, Vybrant ${ }^{\circledR}$ MTT, and CellTiter-Glo ${ }^{\circledR}$ Luminescent, are only measuring the health of a cell and for these assays to be most accurate the maximum difference 
between signal and background needs to be achieved. This occurs for these types of assays when the virus has completely lysed the infected cell monolayer or when cell membranes have become non-functional. The length of time needed to reach this point depends upon the virus. The virus used in this study, HPIV-3, requires seven days to achieve complete cell destruction at the MOI used. However, using an assay that measures a viral expressed reporter gene, the incubation time is only limited to when the reporter gene reaches maximal or acceptable signalto-background ratio levels. For rHPIV3-EGFP, EGFP expression is detectable 24 hours postinfection and reaches its peak at three days in a dose responsive manner. The characteristic syncytia formation of the HPIV-3 virus might be the reason that abundant EGFP expression levels are achieved and remain for five days after the maximum expression levels are reached. Even the lowest dose of virus shown could potentially be used in the antiviral assay, but for the purpose of this study we chose to use a concentration of virus that was equivalent to the concentration of virus used in typical antiviral assays. The broad range of EGFP detection possibilities, in both the length of time and concentration of virus, could potentially be used in experiments that need more defined parameters.

The three-day, EGFP-based assay was evaluated for use in high-throughput assays using $Z^{\prime}$ factor analysis and other parameters. It had a good to excellent $Z$ '-factor value in addition to very high signal-to-background and signal-to-noise ratios. The $Z^{\prime}$-factor takes into account the variability of both the signal and background and the difference between the signal and background. Thus, the virus-expressed EGFP gene is very suitable for this type of assay because only the infected cells will fluoresce and any background measurement seen is due to autofluorescence of the plate, medium, or cells, which can be subtracted from the signal. On the other hand the NR, Vybrant ${ }^{\circledR}$ MTT, and CellTiter-Glo ${ }^{\circledR}$ luminescent assays all measure any intact cells infected or not infected with virus. This can be problematic if the virus does not lyse the cell monolayer completely because the background measurements are raised, reducing the sensitivity and validity of the assay. For example, the CellTiter-Glo ${ }^{\circledR}$ luminescent assay was very susceptible to this phenomenon because even when the cells of the virus controls were completely lysed, as determined visually, significant luminescence was measured when compared to the no-cell control (data not shown), thus the poor signal-to-background and signal-to-noise ratios for the luminescent assay.

When the three-day, EGFP assay was evaluated with a panel of known inhibitors of HPIV-3 WT replication, the assay resulted in excellent sensitivity and marginal specificity. When the rHPIV3-EGFP virus was used in an antiviral assay and fluorescence was measured, approximately an equal number of false positives and true positives would have passed the initial round of antiviral drug screening. However, this is of no concern because in the second round of antiviral drug testing, HPIV-3 WT virus would be used with results being measured by the NR uptake assay. In addition, active compounds could also be further evaluated and validated by virus yield reduction assay or modified plaque reduction assay (Barnard et al., 2004; Matrosovich et al., 2006). Thus, the true, false positives would be detected and eliminated from the drug screening process. It would be more of a concern if the sensitivity were marginal because that would mean that false negative compounds would be eliminated from further testing.

However, some of the differences seen between the SI values determined from the EGFP-based and NR-based assays were due to differences in drug toxicity measured at three and seven days, respectively. The compounds in question seem to be less toxic on day three than on day seven, which implies that the toxicity effects accumulate over time. In addition, cell growth may be slowed leading to apparent cell growth inhibition due to depletion of nutrients and acid build up in the medium after seven days of incubation. These two phenomena probably contributed to the apparent increase in toxicity as measured by the $\mathrm{IC}_{50}$ values in the sevenday, NR assay. Furthermore, because of the additional factors contributing to cell toxicity a 
more accurate assay for detecting cell toxicity is conducted in follow-up studies for active compounds using rapidly-dividing MA-104 cells, which are incubated for 3 days in the absence of virus and measured by NR uptake. In essence, the three-day, EGFP assay may be more accurate compared to the seven-day, NR assay for measuring cell toxicity.

The development of the EGFP assay has increased the sensitivity and quality of the antiviral assay, while shortening the duration and significantly decreasing, although not completely eliminating, the time consuming and labor intensive nature of the NR dye uptake assay. Overall, the use of the rHPIV3-EGFP virus in initial antiviral drug testing reduces the amount of time needed to obtain results and may be beneficial when testing numerous compounds in a highthroughput format. These conclusions warrant the replacement of the HPIV-3 WT virus with the rHPIV3-EGFP virus in initial antiviral testing. Finally, additional research to improve the three-day, EGFP assay might include scaling-up to a 384-well plate format and the development of a non-green fluorescent dye to replace NR in cell toxicity measurements.

\section{Acknowledgments}

We would like to thank Dr. Steven Aust and Dr. Thomas Bunch for their review of the manuscript. We would also like to thank Dr. Craig Day, Brad Schow, Miles Wandersee, Curtis Taylor, Matt Olsen, and Valerie Hubbard for their technical assistance. This work was supported by Contract No. N01 AI-30048 from the Virology Branch, NIAID, NIH.

\section{References}

Barnard DL, Hubbard VD, Burton J, Smee DF, Morrey JD, Otto MJ, Sidwell RW. Inhibition of severe acute respiratory syndrome-associated coronavirus (SARSCoV) by calpain inhibitors and beta-D-N4hydroxycytidine. Antiviral Chem Chemother 2004;15:15-22.

Barnard DL, Stowell VD, Seley KL, Hegde VR, Das SR, Rajappan VP, Schneller SW, Smee DF, Sidwell RW. Inhibition of measles virus replication by 5 '-nor carbocyclic adenosine analogues. Antiviral Chem Chemother 2001;12:241-250.

Calain P, Roux L. The rule of six, a basic feature for efficient replication of Sendai virus defective interfering RNA. J Virol 1993;67:4822-4830. [PubMed: 8392616]

Cattaneo R, Rebmann G, Schmid A, Baczko K, ter Meulen V, Billeter MA. Altered transcription of a defective measles virus genome derived from a diseased human brain. EMBO J 1987;6:681-688. [PubMed: 3582370]

Cavanaugh PF Jr, Moskwa PS, Donish WH, Pera PJ, Richardson D, Andrese AP. A semi-automated neutral red based chemosensitivity assay for drug screening. Invest New Drugs 1990;8:347-354. [PubMed: 2084068]

De Clercq E. Antiviral agents: characteristic activity spectrum depending on the molecular target with which they interact. Adv Virus Res 1993;42:1-55. [PubMed: 8430518]

Durbin AP, Siew JW, Murphy BR, Collins PL. Minimum protein requirements for transcription and RNA replication of a minigenome of human parainfluenza virus type 3 and evaluation of the rule of six. Virology 1997;234:74-83. [PubMed: 9234948]

Finter NB. Dye uptake methods of assessing viral cytopathogenicity and their application to interferon assays. J Gen Virol 1969;5:419-427.

Fuerst TR, Niles EG, Studier FW, Moss B. Eukaryotic transient-expression system based on recombinant vaccinia virus that synthesizes bacteriophage T7 RNA polymerase. Proc Natl Acad Sci USA 1986;83:8122-8126. [PubMed: 3095828]

Galinski, MS. Annotated nucleotide and protein sequences for selected paramyxoviridae. In: Kingsbury, DW., editor. The Paramyxoviruses. Plenum Press; New York: 1991. p. 537-568.

Homann HE, Hofschneider PH, Neubert WJ. Sendai virus gene expression in lytically and persistently infected cells. Virology 1990;177:131-140. [PubMed: 1693801] 
Kraybill, B. 2005.

http://iccb.med.harvard.edu/screening/Quantitative\%20Assay\%20Evaluation\%20and\%

20Optimization\%20complete\%20(3).pdf

Malakhov MP, Aschenbrenner LM, Smee DF, Wandersee MK, Sidwell RW, Gubareva LV, Mishin VP, Hayden FG, Kim DH, Ing A, Campbell ER, Yu M, Fang F. Sialidase fusion protein as a novel broadspectrum inhibitor of influenza virus infection. Antimicrob Agents Chemother 2006;50:1470-1479. [PubMed: 16569867]

Mao H, Thakur CS, Chattopadhyay S, Silverman RH, Gudkov A, Banerjee AK. Inhibition of human parainfluenza virus type 3 infection by novel small molecules. Antiviral Res 2008;77:83-94. [PubMed: 17964670]

Marschall M, Freitag M, Weiler S, Sorg G, Stamminger T. Recombinant green fluorescent proteinexpressing human cytomegalovirus as a tool for screening antiviral agents. Antimicrob Agents Chemother 2000;44:1588-1597. [PubMed: 10817714]

Matrosovich M, Matrosovich T, Garten W, Klenk HD. New low-viscosity overlay medium for viral plaque assays. Virol J 2006;3:63. [PubMed: 16945126]

Noah JW, Severson W, Noah DL, Rasmussen L, White EL, Jonsson CB. A cell-based luminescence assay is effective for high-throughput screening of potential influenza antivirals. Antiviral Res 2007;73:5059. [PubMed: 16904762]

Ohsawa K, Yamada A, Takeuchi K, Watanabe Y, Miyata H, Sato H. Genetic characterization of parainfluenza virus 3 derived from guinea pigs. J Vet Med Sci 1998;60:919-922. [PubMed: 9764404]

Perrotta AT, Been MD. A pseudoknot-like structure required for efficient self-cleavage of hepatitis delta virus RNA. Nature 1991;350:434-436. [PubMed: 2011192]

Pfaffl MW. A new mathematical model for relative quantification in real-time RT-PCR. Nucleic Acids Res 2001;29:2002-2007.

Sidwell, RW. Ribavirin: a review of antiviral efficacy. In: Pandalai, G., editor. Recent Research and Development in Antimicrobial Agents and Chemotherapy. Research Signpost; Kerala: 1996. p. 219-256.

Smee DF, Morrison AC, Barnard DL, Sidwell RW. Comparison of colorimetric, fluorometric, and visual methods for determining anti-influenza (H1N1 and H3N2) virus activities and toxicities of compounds. J Virol Methods 2002;106:71-79. [PubMed: 12367731]

Stokes A, Tierney EL, Murphy BR, Hall SL. The complete nucleotide sequence of the JS strain of human parainfluenza virus type 3: comparison with the Wash/47885/57 prototype strain. Virus Res 1992;25:91-103. [PubMed: 1329377]

Tapparel C, Maurice D, Roux L. The activity of Sendai virus genomic and antigenomic promoters requires a second element past the leader template regions: a motif (GNNNNN)3 is essential for replication. J Virol 1998;72:3117-3128. [PubMed: 9525637]

Towner JS, Paragas J, Dover JE, Gupta M, Goldsmith CS, Huggins JW, Nichol ST. Generation of eGFP expressing recombinant Zaire ebolavirus for analysis of early pathogenesis events and highthroughput antiviral drug screening. Virology 2005;332:20-27. [PubMed: 15661137]

Watanabe W, Konno K, Ijichi K, Inoue H, Yokota T, Shigeta S. MTT colorimetric assay system for the screening of anti-orthomyxo- and anti-paramyxoviral agents. J Virol Methods 1994;48:257-265. [PubMed: 7989442]

Zhang JH, Chung TD, Oldenburg KR. A Simple Statistical Parameter for Use in Evaluation and Validation of High Throughput Screening Assays. J Biomol Screen 1999;4:67-73. [PubMed: 10838414]

Zhang L, Bukreyev A, Thompson CI, Watson B, Peeples ME, Collins PL, Pickles RJ. Infection of ciliated cells by human parainfluenza virus type 3 in an in vitro model of human airway epithelium. J Virol 2005;79:1113-1124. [PubMed: 15613339] 


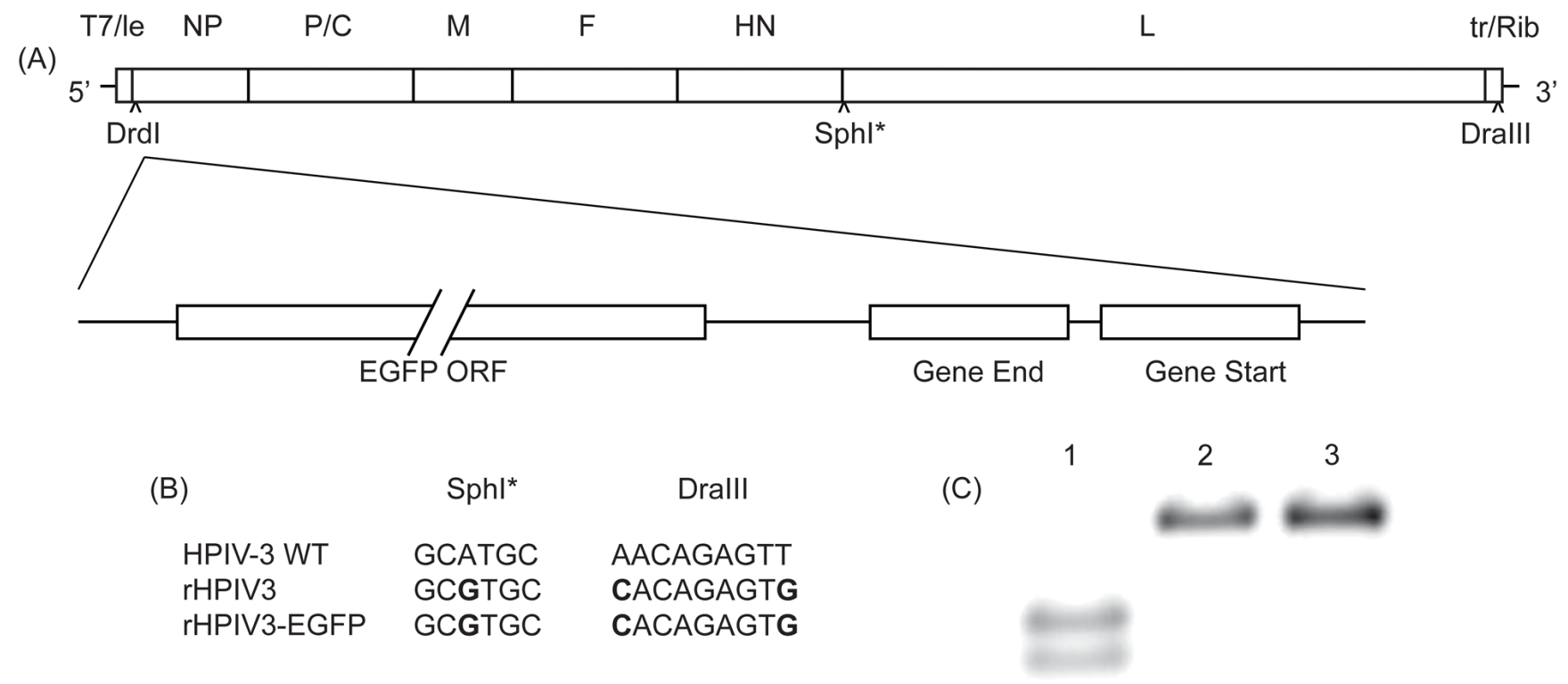

Fig. 1.

EGFP inserted into the rHPIV3 viral antigenome as the first gene. (a) The 852 bp EGFP PCR product was inserted into a natural DrdI site located between the $\mathrm{N}$ gene's start signal and start codon. The reverse primer that was used to amplify EGFP's ORF was designed to encode the HPIV-3 gene end and gene start signals. T7/le indicates that a T7 promoter precedes the rHPIV3 $5^{\prime}$ antigenomic leader sequence. tr/Rib indicates a hepatitis delta ribozyme immediately follows the rHPIV3 $3^{\prime}$ antigenomic trailer sequence. (b) Sequence data showing three intentional mutations and recombinant markers: A to G, destroying a natural SphI site (* indicating destroyed) located in the $5^{\prime}$ noncoding region of the $\mathrm{L}$ gene (a), and $\mathrm{A}$ to $\mathrm{C}$ and $\mathrm{T}$ to $\mathrm{G}$, creation of a unique DraIII site located within the $3^{\prime}$ trailer region (a). (c) Electrophoresis of PCR fragments from HPIV-3 WT (1), rHPIV3 (2), and rHPIV3-EGFP (3) digested with SphI. 
(A)

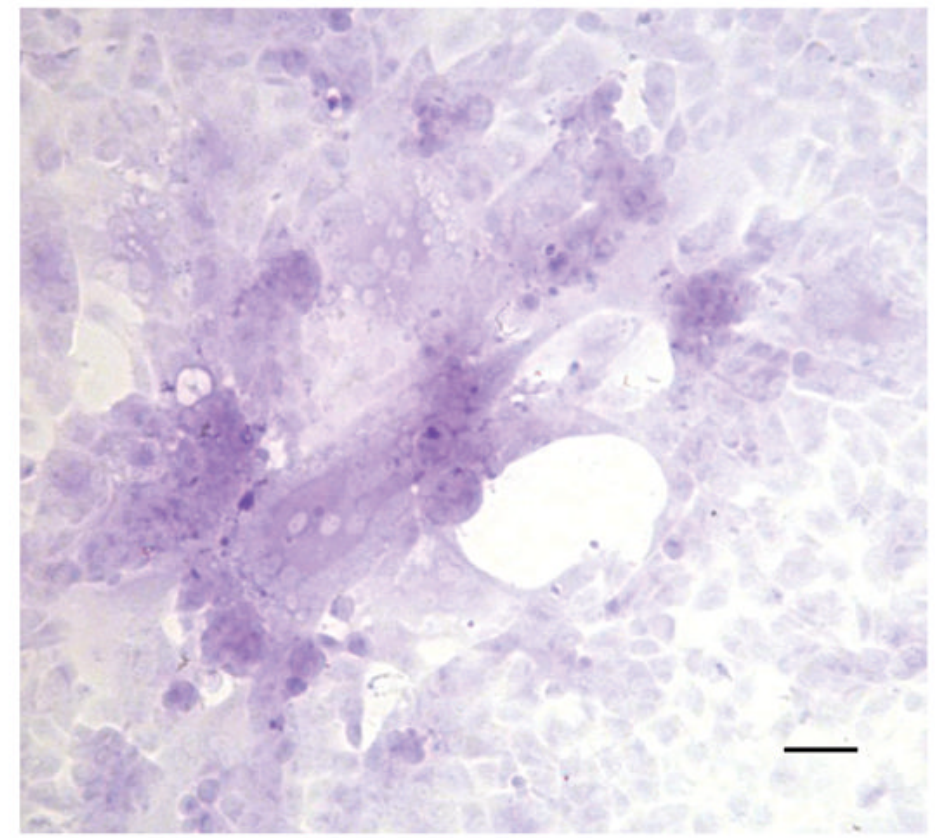

(B)

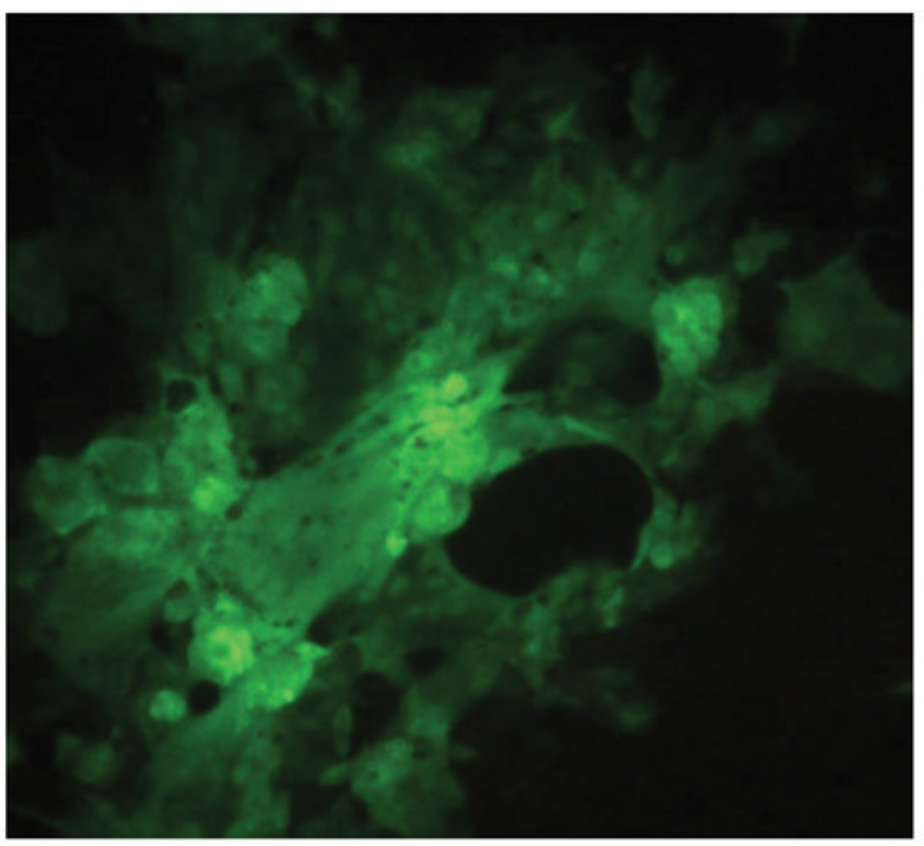

Fig. 2.

MA-104 cells showing an rHPIV3-EGFP induced plaque. (a) Plaque stained with crystal violet and photographed under bright field microscopy. (b) Same plaque photographed under fluorescent microscopy. Scale bar, $50 \mu \mathrm{m}$. 

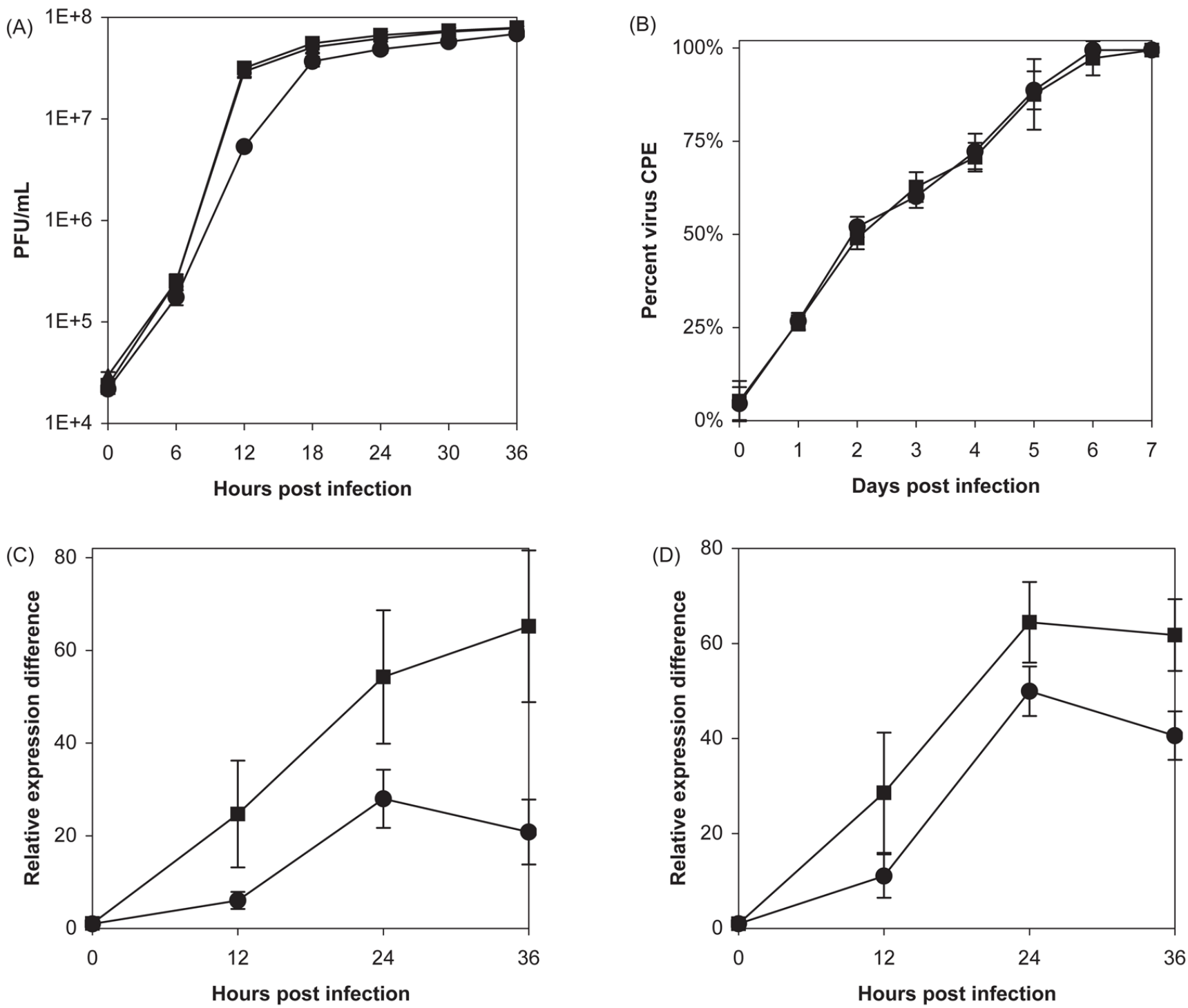

Fig. 3.

Infectious assays comparing the recombinant HPIV-3 virus, expressing EGFP, to the wild-type and recombinant viruses. (a) Single step growth curve. HPIV-3 WT ( $\boldsymbol{\square}), \operatorname{rHPIV} 3(\boldsymbol{\Delta})$, and rHPIV3-EGFP $(\bullet)$ were used to separately infect 12-well plates seeded with MA-104 cells at MOI $=2$. Individual cells were harvested every six hours, including 0 hour, and viral titers were measured by plaque assay. The growth curve for rHPIV3 was not significantly different compared to the growth curve for HPIV-3 WT ( $p>0.01$ ), while the growth curve for rHPIV3EGFP was significantly different compared to the growth curves for HPIV-3 WT and rHPIV3

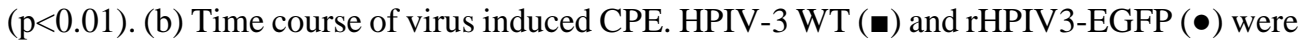
used to infect MA-104 cells at MOI = 0.1 in 96-well plates. Each day, including day 0, the cells of one plate were stained with NR for 2 hours, washed once with PBS, and the NR extracted with ethanol:Sörenson's citrate buffer for 30 min rocking. Absorbance was measured on a spectrophotometer using 540 and $405 \mathrm{~nm}$ wavelengths. Percents were calculated based on NR reduction in infected cells compared to uninfected cell controls. No significant differences were detected ( $p>0.01)$. Relative expression differences in L gene transcription (c) and genomic replication (d) were measured by QRT-PCR. MA-104 cells infected with HPIV-3 
WT ( $\bullet$ and rHPIV3-EGFP $(\bullet)$ were harvested at specified time points. The reverse transcriptase reaction was primed with an HPIV-3 specific primer 5'-

AATTATAAAAAACTTAGGAGTAAAG-3' for genomic replication, which straddles the intergenic region between the fusion and hemagglutinin-neuraminidase genes and anneals to viral, negative-sense, genomic RNA, and a Oligo(dT)20 primer for L gene transcription. The cDNAs were amplified using HPIV-3 specific primers, which were tagged with FAM. Delta$\mathrm{C}_{\mathrm{T}}$ relative expression differences were calculated for each virus at each time point, using the 0 hour measurement for each virus as the calibrator. Significant reductions were seen in rHPIV3-EGFP genomic replication and L gene transcription compared to HPIV-3 WT $(\mathrm{p}<0.01)$. All Y-axis values on all graphs represent the mean \pm S.D. of duplicate assays. 


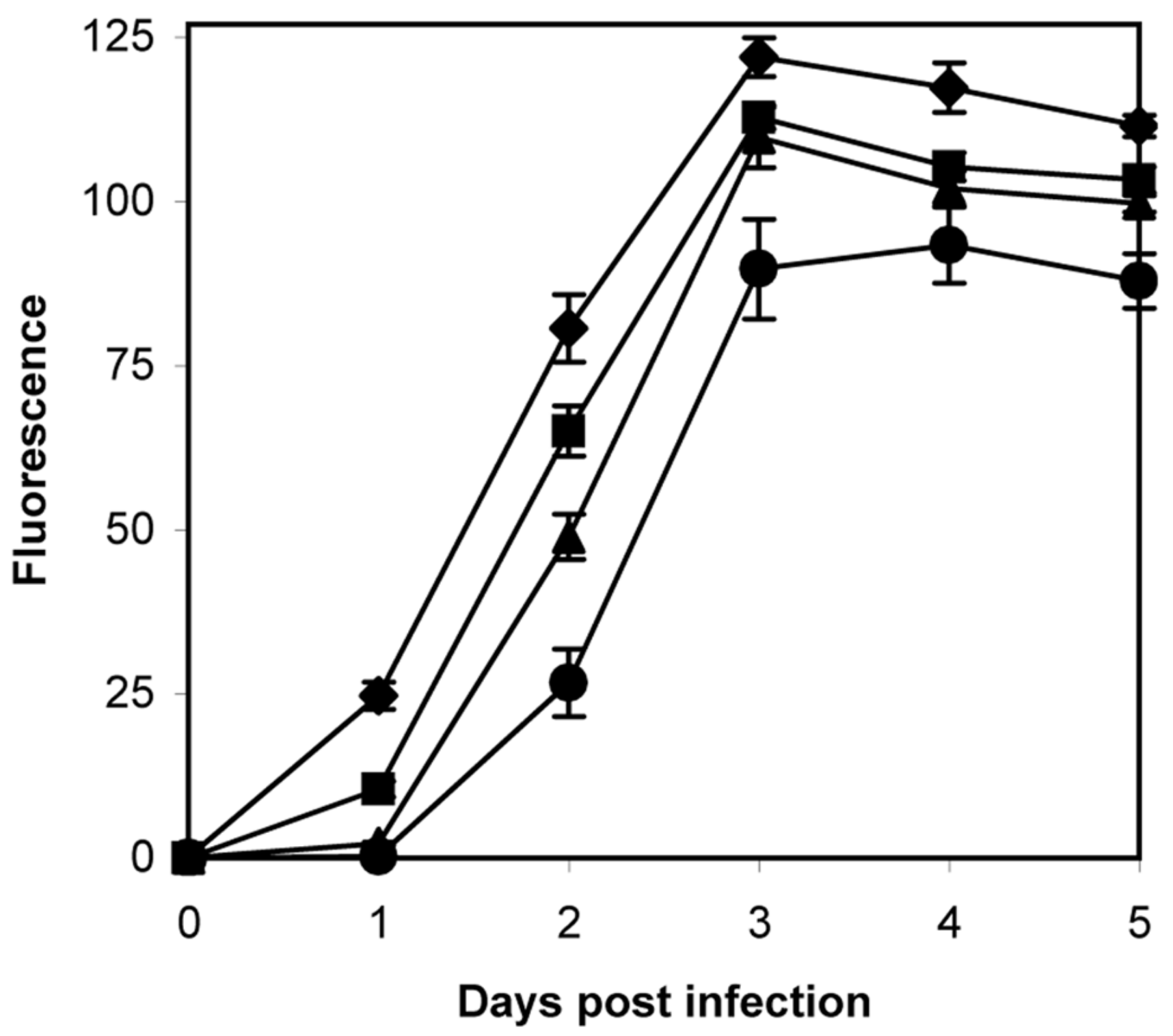

Fig. 4.

EGFP expression curve. 96-Well plates were seeded with MA-104 cells and infected with rHPIV3-EGFP at differing MOIs: $1(\bullet), 0.1(\bullet), 0.01(\boldsymbol{\Delta}), 0.001(\bullet)$. Each day, including day 0 , the cell monolayer was washed once with PBS and fluorescence measured. HPIV-3 WT and rHPIV3 infections were also done in parallel but no fluorescence was detected (data not shown). All Y-axis values represent the mean \pm S.D. of duplicate assays. 
Table 1

Evaluation of the viral expressed EGFP detection method compared to three types of viral CPE detection methods using the rHPIV3-EGFP virus

\begin{tabular}{|c|c|c|c|c|}
\hline & \multirow{2}{*}{$\begin{array}{l}\text { 3-Day Assay } \\
\text { Viral Expressed } \\
\text { EGFP } \\
\text { Fluorescence }\end{array}$} & \multicolumn{3}{|l|}{ 7-Day Assay } \\
\hline & & $\begin{array}{l}\text { Colorimetric } \\
\text { Neutral Red } \\
\text { Uptake }\end{array}$ & $\begin{array}{l}\text { CellTiter-Glo }{ }^{\circledR} \\
\text { Luminescent Cell } \\
\text { Viability }\end{array}$ & $\begin{array}{l}\text { Vybrant }{ }^{\circledR} \text { MTT Cell } \\
\text { Proliferation }\end{array}$ \\
\hline$Z^{\prime}$-factor ${ }^{a}$ & 0.83 & 0.70 & 0.73 & 0.50 \\
\hline Signal-to-Background & 241 & 65 & 6 & 7 \\
\hline Signal-to-Noise & 4057 & 301 & 59 & 60 \\
\hline
\end{tabular}

\footnotetext{
${ }^{a}$ The $\mathrm{Z}^{\prime}$-factor is a statistical calculation that assesses the quality of a high-throughput screening assay and predicts the potential of the assay if the number of samples were scaled up.
} 


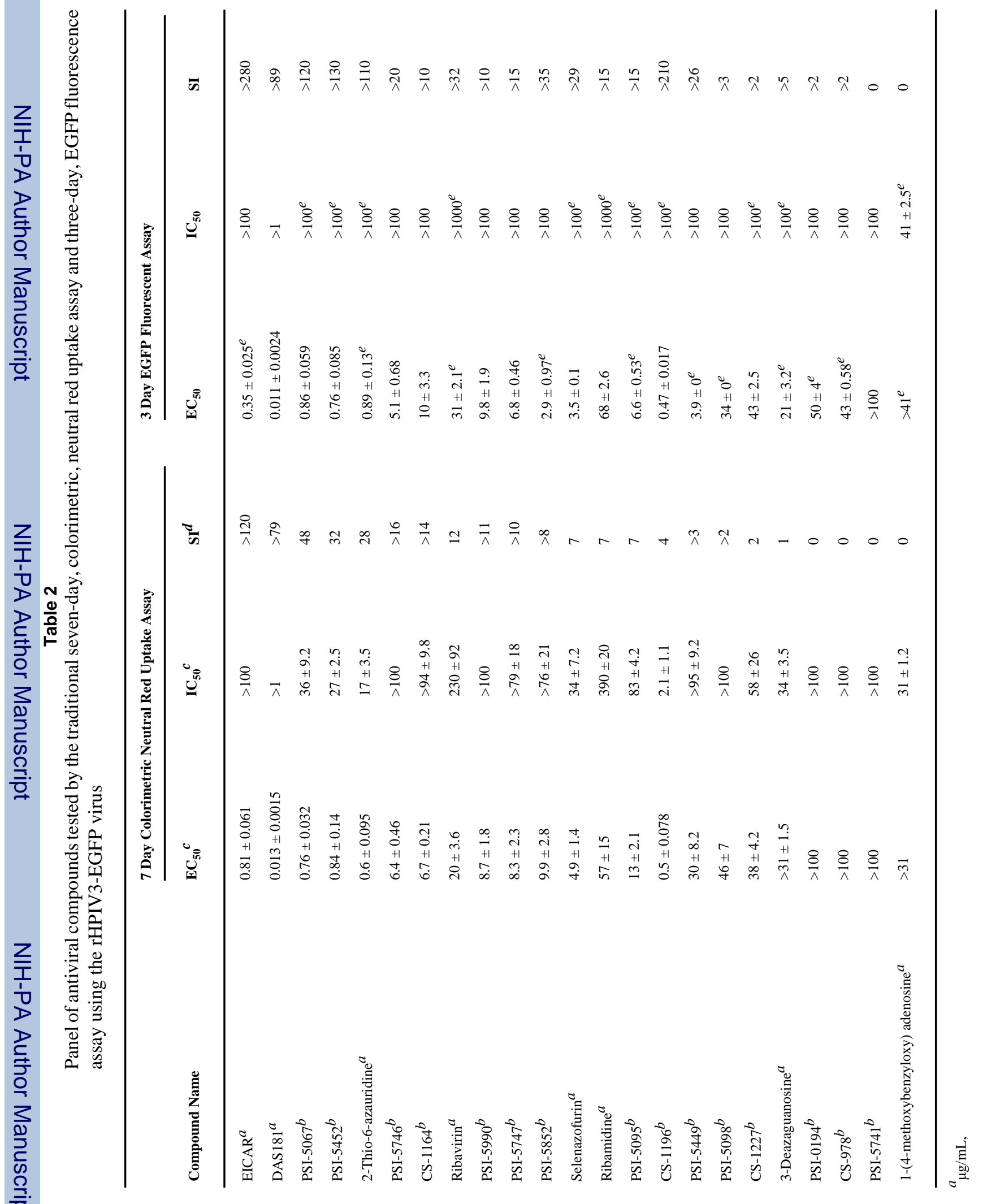


